\title{
Toward On-Line Slag Composition Analysis: Optical Emissions from Laboratory Electric Arc
}

\author{
H. PAUNA, A. TUOMELA, M. AULA, P. TURUNEN, V. PANKRATOV, M. HUTTULA, \\ and T. FABRITIUS
}

Electric arc furnaces and ladle furnaces have an important role in the future of steelmaking where $\mathrm{CO}_{2}$ emissions have to be mitigated to an acceptable level. One way to address this goal is to optimize and improve the current practices by adjusting the chemistry and reactions with material additions or gas injections. These procedures would greatly benefit from on-line slag composition analysis. Since the electric arcs radiate throughout the melting, optical emission spectroscopy is a potential method for such analysis. In this study, optical emissions from the electric arc are measured in a laboratory environment. Dozens of atomic emission lines were correlated with $\mathrm{Cr}_{2} \mathrm{O}_{3}, \mathrm{Fe}_{2} \mathrm{O}_{3}, \mathrm{Al}_{2} \mathrm{O}_{3}, \mathrm{SiO}_{2}, \mathrm{MnO}, \mathrm{MgO}, \mathrm{CaO}, \mathrm{CaF}_{2}, \mathrm{~V}_{2} \mathrm{O}_{5}$, and Ni content of the slag together with correlation between $\mathrm{CaF}_{2}$ and molecular optical emission bands of $\mathrm{CaF}$. Optimal spectral resolution for industrial applications was deducted to be between 0.022 and $0.179 \mathrm{~nm}$.

https://doi.org/10.1007/s11663-021-02382-5

(C) The Author(s) 2021

\section{INTRODUCTION}

PERHAPS the most important, and also the most challenging, effort of the steel industry in the years to come is to make steelmaking more environmentally friendly. ${ }^{[1]}$ One of the main goals is to reduce $\mathrm{CO}_{2}$ emissions, together with increasing both energy and material efficiency. To achieve these goals, improvement of current practices, as well as research on new ideas, are essential. A prominent option for more environmentally friendly steelmaking is electricity-based melting, which has established its place in the global steel production as a steelmaking route with lower $\mathrm{CO}_{2}$ emissions in comparison to the ore-based processes. Electric arc furnaces $(\mathrm{EAFs})$ and ladle furnaces (LFs) are the main units in the melting process chain and the basic raw materials are recycled metal and direct-reduced iron. EAFs have an important role also in the hydrogen reduction process chain, ${ }^{[2,3]}$ which makes them an essential part of the future of steelmaking.

H. PAUNA, M. AULA, and T. FABRITIUS are with the Process Metallurgy Research Unit, University of Oulu, P.O. Box 4300, 90014, Oulu, Finland. Contact e-mail: henri.pauna@oulu.fi A. TUOMELA, P. TURUNEN, and M. HUTTULA are with the Nano and Molecular Systems Research Unit, University of Oulu, P.O. Box 3000, 90014, Oulu, Finland. V. PANKRATOV is with the Institute of Solid State Physics, University of Latvia, 1063, Riga, Latvia.

Manuscript submitted June 28, 2021; accepted November 7, 2021.

Article published online December 7, 2021.
At present, roughly a third of global steel is produced with EAFs. ${ }^{[4]}$ To further optimize the process and increase efficiency, many problems remain to be solved. One problem, which the furnace operator can affect during the melting, is to optimize the amount and species of additive materials that are injected and charged into the furnace. ${ }^{[5]}$ With these additions, the operator can adjust the chemical reactions inside the furnace so that the final quality of the steel satisfies the strict requirements. However, the composition of the slag, which contains the impurities from the charge material and forms a slag surface on top of the molten bath, is not exactly known during the melting with the traditional analysis methods. A commonly used slag composition analysis method is X-ray fluorescence (XRF), which requires sampling and sample preparation. Information on the slag composition during the melting may be based on e.g., modeling or personal experience of the furnace operator. Since the chemistry of the slag has a significant effect on the steel composition, a more profound knowledge of the slag composition would increase both material and energy efficiency. Furthermore, the amount of valuable alloying elements, such as chromium, could be reduced in the slag.

One of the main obstacles in the way of on-line slag composition analysis is the extreme environment of an industrial furnace. However, optical emission spectroscopy (OES) has proven to be a viable method to obtain element-sensitive data from industrial $\mathrm{EAFs}^{[6-8]}$ and LFs. ${ }^{[9]}$ The optical emissions are measured directly from the arc's plasma, in which material decomposes to 
atoms and molecules that emit light with wavelengths that are characteristic of each particle. The slag components that evaporate into the plasma can be identified from the optical emission spectra. In addition to arc studies, optical measurements have proven to be beneficial in e.g., converter mouth flame measurements ${ }^{[10]}$ and LF slag sample characterization. ${ }^{[1]}$ In this work, OES is studied as a slag composition analysis method for electric arc steelmaking based on laboratory arc spectra from slag samples. In addition to an abundance of atomic optical emissions from slag components, also molecular optical emission bands of CaF were observed in situ. Due to the high application potential in the steel industry, the results have been discussed from industrial practicability and online analysis point of view.

\section{METHODS AND MATERIALS}

EAF and LF slag samples from two European steel plants were used in this study. The EAF slag samples were from high-alloyed steel grades, whereas the LF slag samples were from both the high-alloyed and carbon steel grades. The EAF high-alloyed steel grade, LF carbon steel grade, and LF high-alloyed steel grade are referred to as grades 1, 2, and 3, respectively. Slag compositions of each sample were obtained with XRF as part of the standard slag composition analysis of the steel plants. All slag compositions have been normalized with respect to the highest value for each slag component for confidentiality purposes.

The measurements were carried out with a small-scale EAF at the laboratory of the Nano and molecular systems research unit at the University of Oulu. Figure 1 demonstrates the view into the chamber. Optical emission was recorded by using a commercial Andor Solis SR-500 Czerny-Turner type spectrometer. The spectrometer with $0.06 \mathrm{~nm}$ optical resolution contains three gratings with line densities $1501 / \mathrm{mm}, 6001 / \mathrm{mm}$, and $1200 \mathrm{l} / \mathrm{mm}$. During the experiments, two gratings with

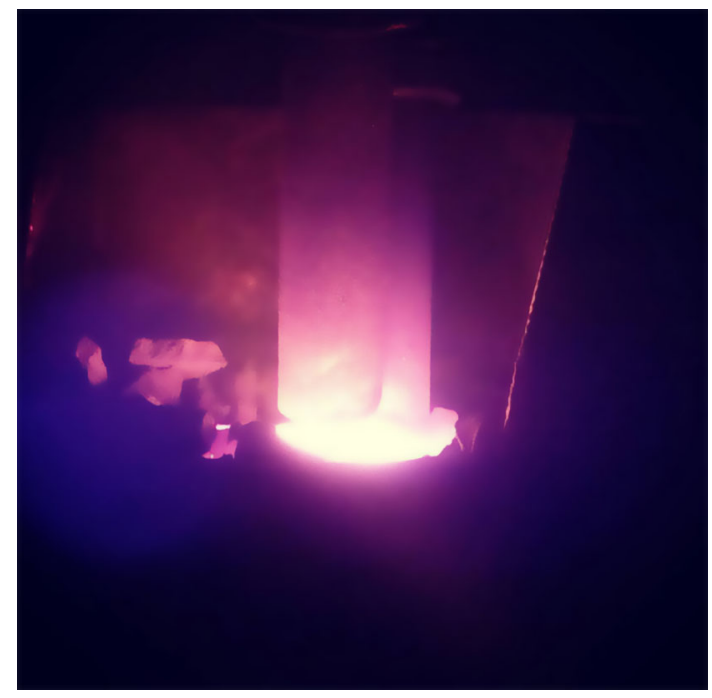

Fig. 1-View into the measurement chamber.
$150 \mathrm{l} / \mathrm{mm}$ and $600 \mathrm{l} / \mathrm{mm}$ were used. The slit of the spectrometer was kept as small as possible $(10 \mu \mathrm{m})$ in order to avoid any damage caused by a bright electric arc. The optical emissions were collected with Ocean Optics QP600-2SR optical fiber, connected to the spectrometer. The spectrometer was equipped with an ultraviolet (UV) sensitized Newton DU940N charge-coupled device camera. The camera was cooled to $-45^{\circ} \mathrm{C}$ by an electric Peltier element in order to minimize dark current. Andor Solis for Imaging software was used for verifying the parameters of the measurement as well as for observing the results.

Spectra with less than $50 \mathrm{~nm}$ wavelength range were taken at 190-236, 234-280, 278-325, 323-369, 368-414, 412-459, 457-503, 502-548, 545-590, 590-634, 634-679, and $678-722 \mathrm{~nm}$. These spectra are referred to as narrow spectra. Additionally, longer-range spectra were taken in 377-745 and 450-817 $\mathrm{nm}$. These spectra are referred to as broad spectra. Both the narrow and broad spectra had 2048 pixels. The narrow spectra were taken in order to have a finer spectral resolution for the identification of suitable emission lines for slag composition analysis. The broad spectra, on the other hand, represent the spectra that would more probably be measured in industrial applications where the number of spectrometers is limited, but as many relevant optical emission lines as possible should be accounted for in the spectra.

The vacuum-allowed chamber consists of a sample holder, which can be adjusted in the vertical direction and rotated in the horizontal direction. The sample holder was cooled by using a water-cooled copper conductor, covering the holder. For heating the sample and generating the electric arc, two graphite bars were adjusted on the top of the sample holder. The graphite bars were cooled by using water-cooled copper tubes. The AC voltage between the graphite bars was generated by a general welding power supply (Kemppi MasterTig AC/DC2000), attached to the copper tubes. Before measurements, the chamber was pumped by using an oil-free scroll pump. After the pumping process, the chamber was filled with nitrogen gas slightly above the atmospheric pressure. The signal was collected by the optical fiber, which was attached inside the chamber and focused on the sample holder and the graphite bars where the electric arc was generated. The fiber was inside in order to avoid any distortions in the spectrum, which could be caused by the glass between the fiber and the sample. The number of slag samples for each steel grade is listed in Table I.

\section{THEORETICAL}

Due to the high energy of the electric arc, material from the slag, atmosphere, and electrodes evaporate into the arc's plasma. The material decomposes into atoms and molecules, which emit light at characteristic wavelengths. Thus, atoms and molecules can be identified from an optical emission spectrum, where the optical emission intensities are presented as a function of wavelength. Element-specific wavelengths for optical emissions are thoroughly listed in the NIST Atomic 
Table I. The Number of Slag Samples for Each Steel Grade with Respect to the Spectrum Wavelength Range

\begin{tabular}{lccc}
\hline Grade & Narrow Spectra & 377 to $745 \mathrm{~nm}$ & 450 to $817 \mathrm{~nm}$ \\
\hline 1 & 9 & 9 & 9 \\
2 & 9 & 3 & 7 \\
3 & 10 & 9 & 9 \\
\hline
\end{tabular}

Spectra Database. ${ }^{[12]}$ An atomic emission line is described by its source, ionization degree, and wavelength. The source is the element that emits the light. Ionization degree describes how many electrons the atom has lost and is labeled with Roman numerals, where the first three degrees I, II, and III correspond to neutral, singly ionized, and doubly ionized atoms, respectively. For example, an atomic optical emission from singly ionized calcium at $393.37 \mathrm{~nm}$ would be labeled Ca II 393.37.

Optical emission lines from a plasma source can be susceptible to self-absorption, where the emitted light is absorbed by other particles, leading to distortion and broadening of the line. ${ }^{[13]}$ This can happen for example when an atom emits light in the hotter center of the plasma and then another atom of the same element absorbs the light in the cooler edges of the plasma. Self-absorption may also be so extensive that self-reversal occurs, where the emissions are so intensively absorbed that the emission line intensity starts to decline around the central wavelength of the emission ${ }^{[14]}$ Strong self-absorption and self-reversal of $\mathrm{Ca}$ II lines were observed in this study. In an extreme environment and harsh atmospheres, such as those in industrial EAFs and LFs, this phenomenon has to be taken into account.

The emission lines have been fitted with Gaussian functions

$$
F=A \times \exp \left(-\frac{(x-B)^{2}}{C^{2}}\right),
$$

where $\mathrm{A}, \mathrm{B}$, and $\mathrm{C}$ are constants that are connected to the line's height, central wavelength, and full-width at half maximum (FWHM). The intensity of the emission line is obtained by integrating (Table I). In cases where the emission lines are so close to each other that their intensity profiles overlap, multiple Gaussians have to be fitted in order to distinguish individual lines from the spectrum.

\section{RESULTS AND DISCUSSION}

\section{A. OES Slag Analysis with Narrow Spectra}

Figure 2 represents 13 individual spectra with less than $50 \mathrm{~nm}$ wavelength range. These ranges have been listed in the Methods and materials section. The spectra hold hundreds of atomic and several molecular optical emissions. From an industrial viability point of view, this sets constraints for the emission lines that can be used in the slag composition analysis. First of all, due to the vast amount of optical emissions, emission lines will regularly overlap with each other. The fitting of multiple functions, such as Gaussian, Lorentzian, or Voigt profiles, can result in misinterpretation of the line intensities. The most suitable emission lines for accurate slag composition analysis are those that are as isolated as possible from neighboring emission lines. Secondly, fitting multiple overlapping functions increases the computation time. In an on-line measurement system, the computation time should be kept at a practicable limit.

The FWHM values of $\mathrm{Ca}$ II emission lines near 395 $\mathrm{nm}$ were observed to increase with increasing $\mathrm{CaF}_{2}$ content of the slag. Furthermore, the Ca II lines also started to show strong self-reversal with increasing $\mathrm{CaF}_{2}$ content. Figure 3(a) displays the spectra with respect to $\mathrm{CaF}_{2}$ and (b) the linear fit that can be plotted between the FWHM of the Ca II line at $393.366 \mathrm{~nm}$ and the $\mathrm{CaF}_{2}$. Three spectra were excluded from the fit due to strong general self-absorption and self-reversal of the whole UV region below $400 \mathrm{~nm}$. When the FWHM values were compared to the $\mathrm{CaO}$ content of the slag, the FWHM values were vaguely distributed below 0.5 $\mathrm{nm}$ for lower $\mathrm{CaO}$ content and above 0.5 for higher $\mathrm{CaO}$ content. High self-absorption and self-reversal relates to the increasing number of ionized calcium atoms in the plasma, indicating that $\mathrm{CaF}_{2}$ content contributes to the amount of ionized calcium in the plasma.

It should be noted that the spectra with less than 50 $\mathrm{nm}$ wavelength range, such as those of Figure 2, have been measured separately from one another and are not from the same plasma. Thus, the intensities of the emission lines from different wavelength ranges turned out not to be comparable. The FWHM values of the lines, however, could be compared between all the wavelength ranges as the FWHM proved to be more sensitive to the changes in the slag composition than the changes in the overall spectrum intensity. The atomic emission lines that were used in the slag composition analysis with the narrow spectra have been presented in Appendix Table AI for several slag components. The reference slag component was chosen to be $\mathrm{MgO}$ based on the equilibrium composition computation of Reference 9.

Nine examples of XRF slag component ratios with respect to emission line FWHM ratios are presented in Figure 4. All of the line ratio FWHM values could not be used in the analysis. Clear outliers were identified to be caused by overlap with neighboring lines, self-absorption or self-reversal of the line, and saturation of the spectrum intensities. The outliers have FWHM ratio values equal to zero in Figure 4. In addition to the examples of Figure 4, more ratio results have been tabulated in Appendix Table AI. The number of slag samples (\#S) that have been used in the ratio analysis together with outliers $(\# \mathrm{O})$ are marked in these tables. The $\mathrm{R}^{2}$ values have been obtained with linear fitting between the \#S and the XRF slag component ratios. 


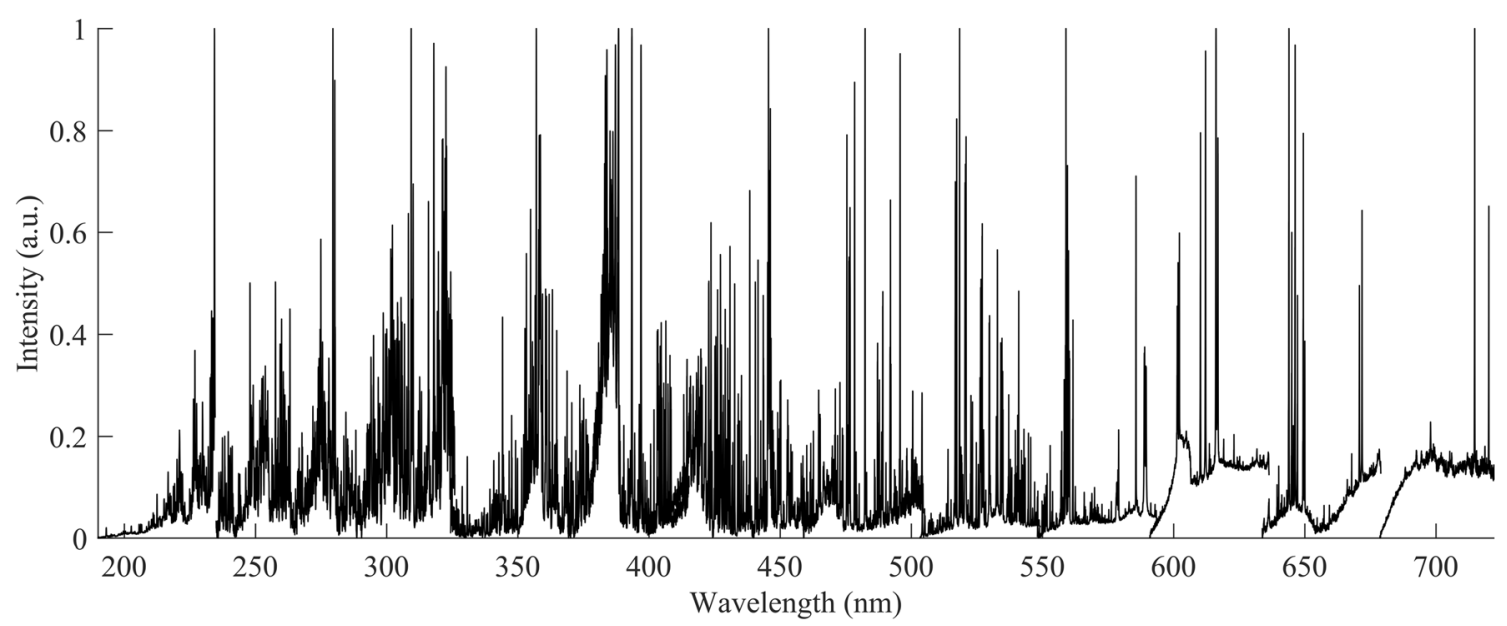

Fig. 2-13 narrow spectra from same slag sample. All individual spectra have been normalized.

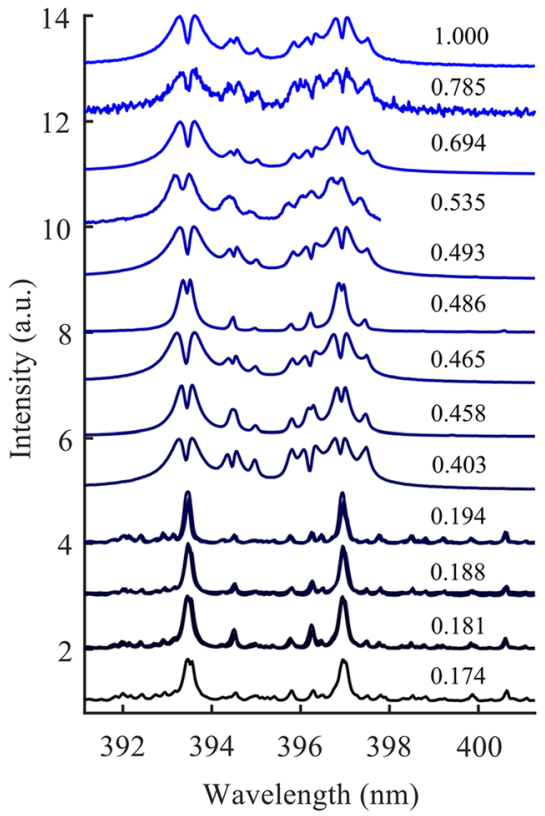

(a)

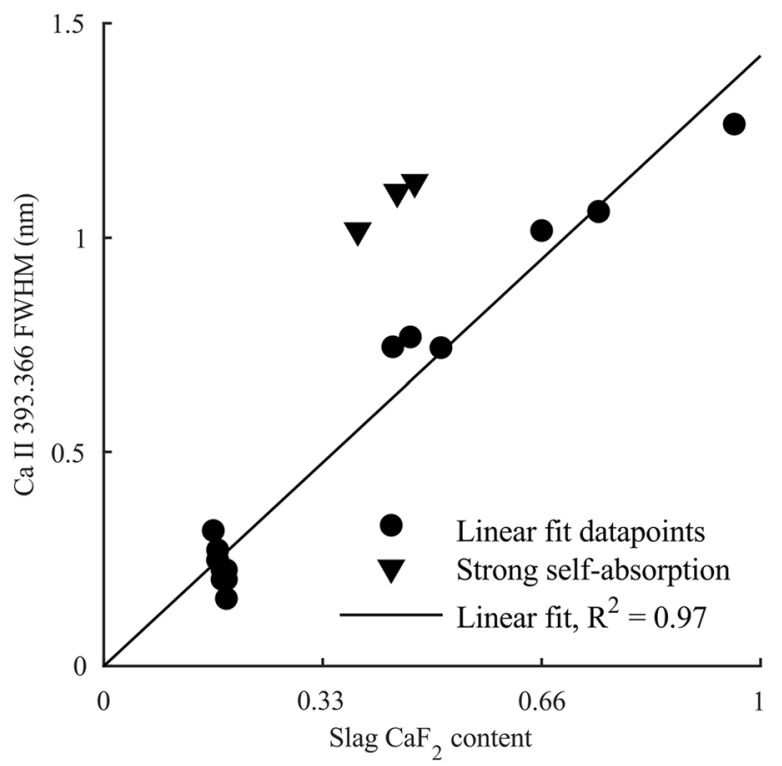

(b)

Fig. 3- (a) Spectra with increasing $\mathrm{CaF}_{2}$ slag content and $(b)$ a linear fit between the FWHM of Ca II 393.366 emission line and slag $\mathrm{CaF}_{2}$ content. $\mathrm{CaF}_{2}$ content have been marked above the spectra. Three spectra were excluded from the relation due to strong self-absorption of the whole UV region. The slag contents have been normalized with respect to the highest value for each slag component.

\section{B. OES Slag Analysis with Broad Spectra}

Two spectra within the wavelength ranges $377-745$ and $450-817 \mathrm{~nm}$ are displayed in Figure 5. The spectra are dominated by atomic optical emissions with several broader emission bands. An abundance of Ca I, Ca II, $\mathrm{Fe} \mathrm{I}, \mathrm{Cr} \mathrm{I}$, and $\mathrm{Mn}$ I together with several intensive $\mathrm{Mg}$ I, Ti I, V I, Na I, K I, and Li I lines can be identified within wavelengths from 377 to $817 \mathrm{~nm}$. Additionally, a few Al I and Si I lines are located near $395 \mathrm{~nm}$. The wavelength range $377-817 \mathrm{~nm}$ has been observed to be clearly visible in pilot-scale $\mathrm{EAF},{ }^{[15]}$ industrial EAF, ${ }^{[8]}$ and industrial LF. ${ }^{[9]}$ To increase the light acquisition in the UV region, a light-gathering lens that permeates UV light can be used. With a light-gathering lens, spectra could be observed as low as $350 \mathrm{~nm}$ in industrial LF OES measurements. ${ }^{[9]}$

The spectra that were measured in this study were compared to spectra of other researchers in order to identify the molecular optical emissions. Bol'shakov et al. ${ }^{[16]}$ studied $\mathrm{CaO}$ and $\mathrm{CaF}_{2}$ separately with laser-induced breakdown spectroscopy (LIBS). Their spectrum of $\mathrm{CaO}$ formed a very broad emission band between 590 and $650 \mathrm{~nm}$ and a smaller one between 545 and $565 \mathrm{~nm}$. The molecular optical emissions from $\mathrm{CaF}$, on the other hand, display a clearer band structure centered around $535,585,605$, and $625 \mathrm{~nm}$. Similar results for $\mathrm{CaF}$ have been reported, to name a few, by Gaft et at., ${ }^{[17]}$ Alvarez-Llamas et at., ${ }^{[18,19]}$ and Pořizka et at. ${ }^{[20]}$ in 


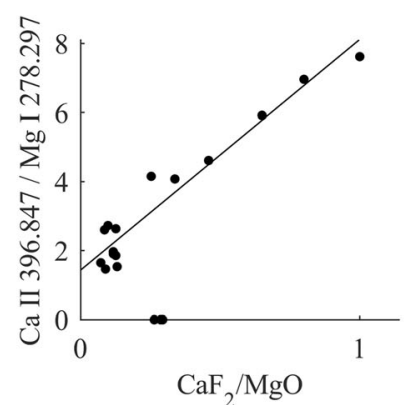

(a)

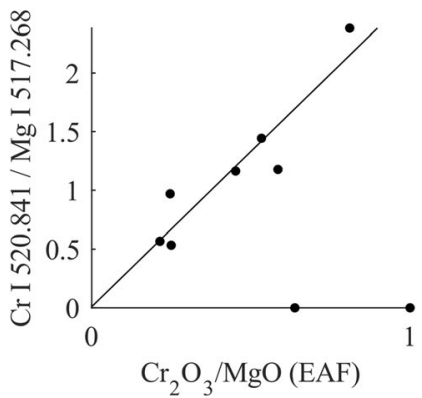

(d)

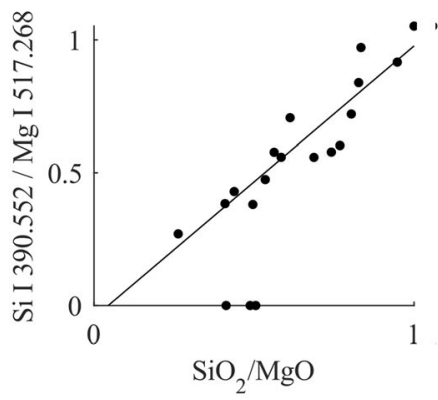

(g)

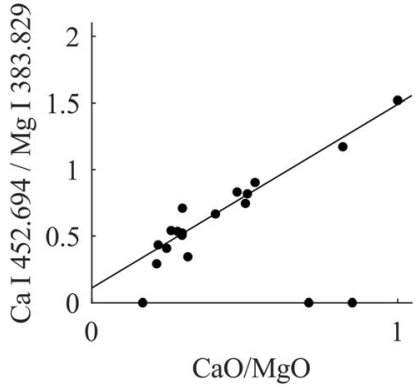

(b)

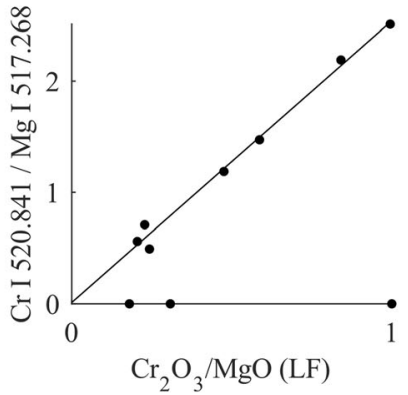

(e)

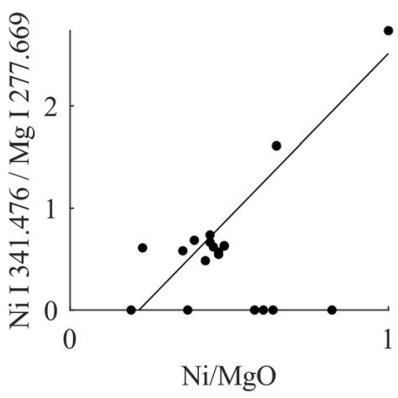

(h)

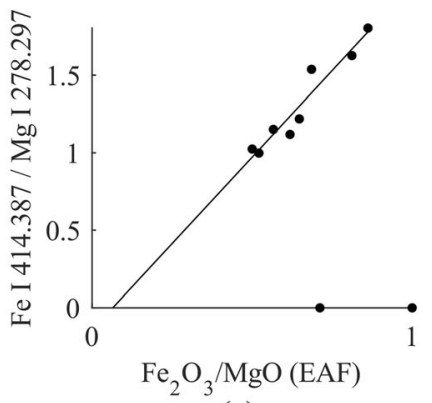

(c)

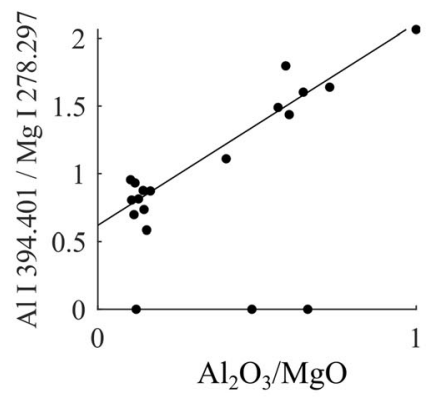

(f)

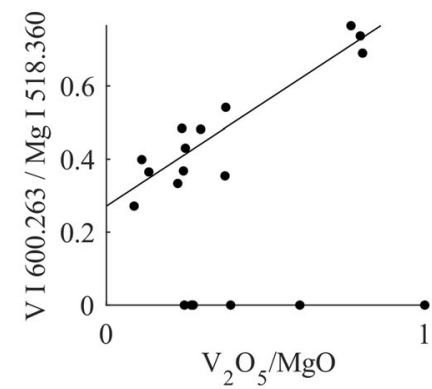

(i)

Fig. 4-(a) to (i) Example XRF slag composition ratios with respect to emission line FWHM ratios for several slag components. The slag component ratios have been normalized with respect to the highest value for each ratio.

their LIBS studies. The CaF molecular emissions between 530 and $630 \mathrm{~nm}$ arise from molecular transitions $B^{2} \Sigma^{+} \rightarrow X^{2} \Sigma^{+}$(band at $535 \mathrm{~nm}$ ) and $A^{2} \Pi \rightarrow$ $X^{2} \Sigma^{+}$(bands at 585, 605, and $625 \mathrm{~nm}$ ). ${ }^{[16-19,21]}$ Regarding the $\mathrm{CaO}$ band in the spectrum of Bol'shakov et al., the spectrum between 377 and $745 \mathrm{~nm}$ in Figure 5 shows a similar broad band between 590 and $650 \mathrm{~nm}$. Even though there was $\mathrm{CaO}$ in every slag sample, the $\mathrm{CaO}$ band was not intensive enough to be detected in all of the spectra in the present study. As emphasized also by Alvarez-Llamas et at. ${ }^{[18,19]}$ and Vogt et al., ${ }^{[21]} \mathrm{CaF}$ bands above $590 \mathrm{~nm}$ overlap with $\mathrm{CaO}$ bands, and thus the $\mathrm{CaF}$ bands at 535 and $585 \mathrm{~nm}$ show more promise for reliable quantitative analysis.

Poŕizka et al. ${ }^{[20]}$ discuss the problems of measuring atomic fluorine, and halogens in general, with LIBS due to high excitation energy and absorption of its UV emissions in the air. To overcome this obstacle, they successfully analyzed the optical emissions of $\mathrm{CaF}$, which may form e.g., via recombination of fluorine and calcium in the plasma, instead of atomic optical emissions. Alvarez-Llamas et $a .^{[18,19]}$ had a similar approach to quantify the fluorine content of samples with CaF bands. Vogt et al. ${ }^{[21]}$ demonstrate well in their LIBS studies how the CaF can be observed even though $\mathrm{CaF}_{2}$ itself is not present in the sample. They noticed also that the intensity of the $\mathrm{CaF}$ band decreased if $\mathrm{CaF}_{2}$ was present in the sample in comparison to the sample without $\mathrm{CaF}_{2}$. In the case of $\mathrm{CaCl}_{2}$, an increase in $\mathrm{CaCl}_{2}$ content of the sample led to an increase in the $\mathrm{CaCl}$ molecular emission band intensity. One reason for this was deduced to be the differences in the dissociation energies of $\mathrm{CaCl}_{2}$ and $\mathrm{CaF}_{2}$, but they concluded that further research is required for a thorough understanding of the phenomenon. Aside from the LIBS studies, the benefit of $\mathrm{CaF}$ bands in the analysis of fluorine content is known also in arc studies. Optical emissions from $\mathrm{CaF}$, originated from $\mathrm{CaF}_{2}$ or recombination of calcium and fluoride, in arcs were studied already in the $1930 \mathrm{~s}$ and $1970 \mathrm{~s}$ by Papish et al. ${ }^{[22]}$ and Troshkina et al., ${ }^{[23]}$ whereas the earliest $\mathrm{CaF}$ flame studies date back to impressive research of Mitscherlich ${ }^{[24]}$ in 1864. 


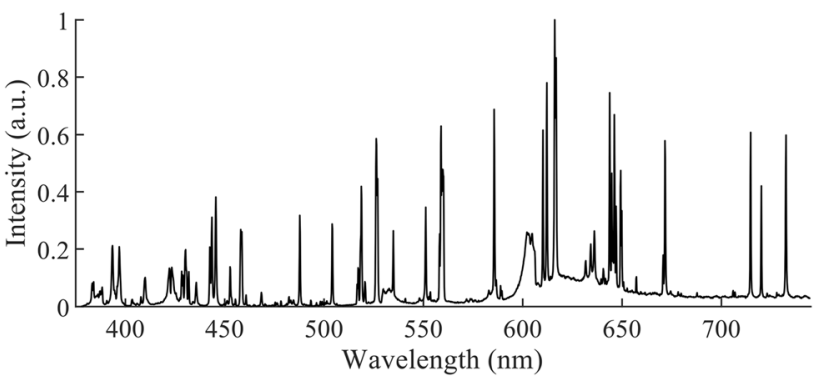

(a)

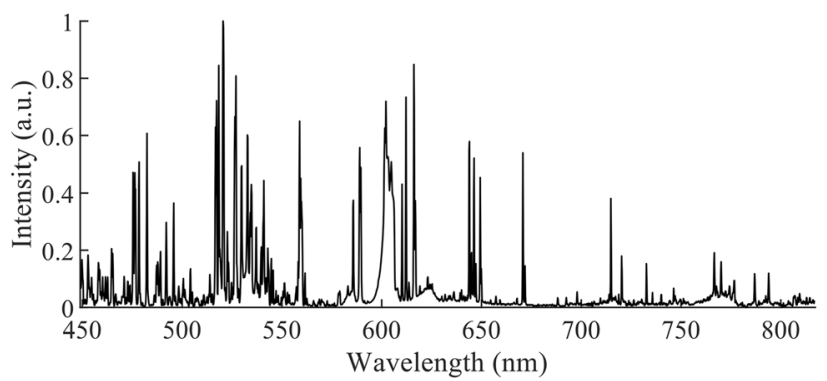

(b)

Fig. 5- Spectra within wavelength ranges (a) 377 to 745 and (b) 450 to $817 \mathrm{~nm}$.

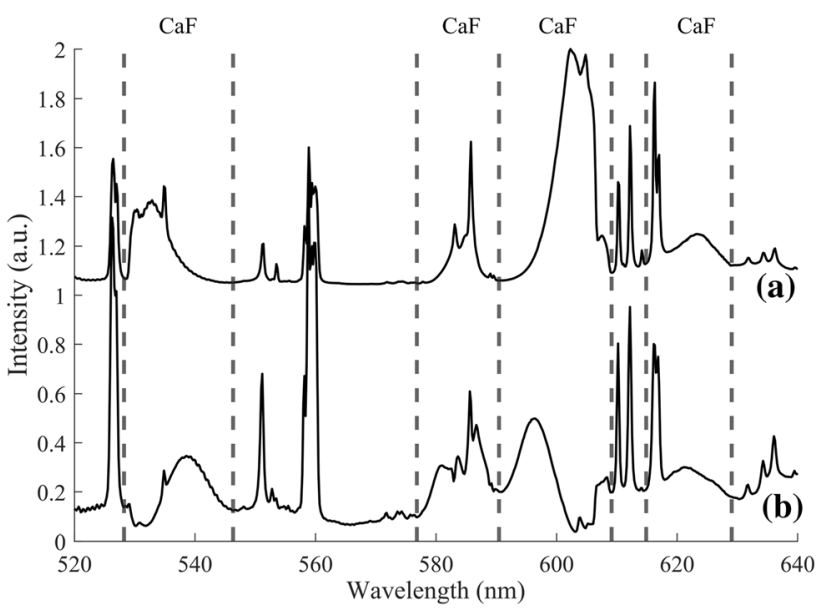

Fig. 6-Example spectra with (a) no self-reversal of $\mathrm{CaF}$ bands and (b) clear self-reversal of $\mathrm{CaF}$ bands near central wavelengths 535 and $605 \mathrm{~nm}$. Wavelength ranges for $\mathrm{CaF}$ optical emissions have been marked in the graph.

Both of the spectra in Figure 5 have a similar band structure as the $\mathrm{CaF}$ bands around 535, 585, 605, and $625 \mathrm{~nm}$. However, the band near $605 \mathrm{~nm}$ overlaps with intense $\mathrm{Mn}$ I lines centered between 601 and $603 \mathrm{~nm}^{[12]}$ and possibly with $\mathrm{Mn}^{2+}$ optical emission centered near $600 \mathrm{~nm} \cdot{ }^{[25-28]} \mathrm{A}$ magnification of the wavelength range where the $\mathrm{CaF}$ bands are observed can be found in Figure 6 where (a) shows the characteristic CaF molecular band structures, whereas in (b) the emission bands centered at 535 and $605 \mathrm{~nm}$ are strongly self-reversed and the band at $585 \mathrm{~nm}$ suffers from both self-absorption and self-reversal. It should be pointed out that the intensity profiles at $530-545 \mathrm{~nm}$ and $590-600 \mathrm{~nm}$ in Figure 6(b) are not molecular bands from different species. These are part of the $\mathrm{CaF}$ bands centered at 535 and $605 \mathrm{~nm}$, respectively. Since the self-reversal is strongest at the central wavelengths of the bands, emissions outside of the central wavelength do not suffer as much from the self-absorption or self-reversal. In this case, the self-reversal starts to affect these bands below $539 \mathrm{~nm}$ and above $596 \mathrm{~nm}$, respectively, thus creating the broad band-like structures to spectrum intensity at 530-545 $\mathrm{nm}$ and 590-600 nm.

The intensity of the CaF emission band near $535 \mathrm{~nm}$ has been studied with respect to the $\mathrm{CaF}_{2}$ slag content in Figure 7(a). The intensity of the emission band is negative if the band is self-reversed. The intensity turned out to decrease with increasing $\mathrm{CaF}_{2}$ content with a non-linear relation. Six slag samples were not used in the correlation analysis due to low $\mathrm{CaF}_{2}$ content in the slag, where the structure of the $\mathrm{CaF}$ band near $535 \mathrm{~nm}$ could not be identified. The $\mathrm{Ca}$ I line at $534.947 \mathrm{~nm}$ has been excluded from the correlation analysis. Figure 7(b) shows the $\mathrm{CaF}$ band centered around $585 \mathrm{~nm}$. The band structure is interfered by an intensive $\mathrm{Ca} \mathrm{I}$ emission line near $586 \mathrm{~nm}$ and $\mathrm{Na}$ I lines near $588 \mathrm{~nm}$. The intensity of the CaF band with respect to the slag $\mathrm{CaF}_{2}$ content was evaluated with the wavelength ranges 2 and 3 in Figure 7(b). Some of the spectra had to be excluded from the analysis due to interference from intensive atomic emission lines or saturation of spectrum intensity. The self-reversal of the peak at wavelength range 3 is evident from the negative intensity values of Figure 7(b).

To address the overlapping of $\mathrm{Mn} \mathrm{I}, \mathrm{CaF}$ band, and $\mathrm{Mn}^{2+}$ optical emissions, the intensity of the spectrum was studied near $605 \mathrm{~nm}$. The broad emission band that can be seen in the Figures 5 and 6 and its intensity with respect to $\mathrm{MnO}$ and $\mathrm{CaO}$ content of the slag are presented in Figure 7(c). One spectrum was excluded from the relations due to saturated intensity and five due to the absence of the broad band near $605 \mathrm{~nm}$. This band did not show any relation to the $\mathrm{CaF}_{2}$ content of the slag, which can be explained with the overlap of the $\mathrm{CaF} 605$ band with the $\mathrm{Mn} \mathrm{I}$ lines, $\mathrm{CaO}$ band, and possibly $\mathrm{Mn}^{2+}$. Furthermore, the $\mathrm{CaO}$ and $\mathrm{MnO}$ contents of the slag have a negative correlation with each other with $\mathrm{R}^{2}=0.94$, which could explain why this emission band seems to correlate with $\mathrm{CaO}$ even though a clear $\mathrm{CaO}$ band was not observed in many spectra. Since the $\mathrm{CaO}$ emission band in the works of Bol'shakov et al. ${ }^{[16]}$ and Gaft et al. ${ }^{[17]}$ spanned from 590 to $650 \mathrm{~nm}$, the results of Figure 7(c) are probably related to the Mn I lines or $\mathrm{Mn}^{2+}$. Whether the relation of Figure 7(c) arises from the $\mathrm{Mn}$ I lines, $\mathrm{Mn}^{2+}$ optical emission, or both, could not be determined.

Similar to narrow spectrum analysis, several line ratios were determined from the broad spectra in order to assess their relation to the slag composition. These results are presented in Appendix Table AII in the same manner as for the narrow spectra. Figure 8 shows example line ratios for several slag components. Due to lower spectral resolution in comparison with the narrow spectra, the number of emission lines in the ratio analysis is significantly lower. Several feasible Ca I, Ca 

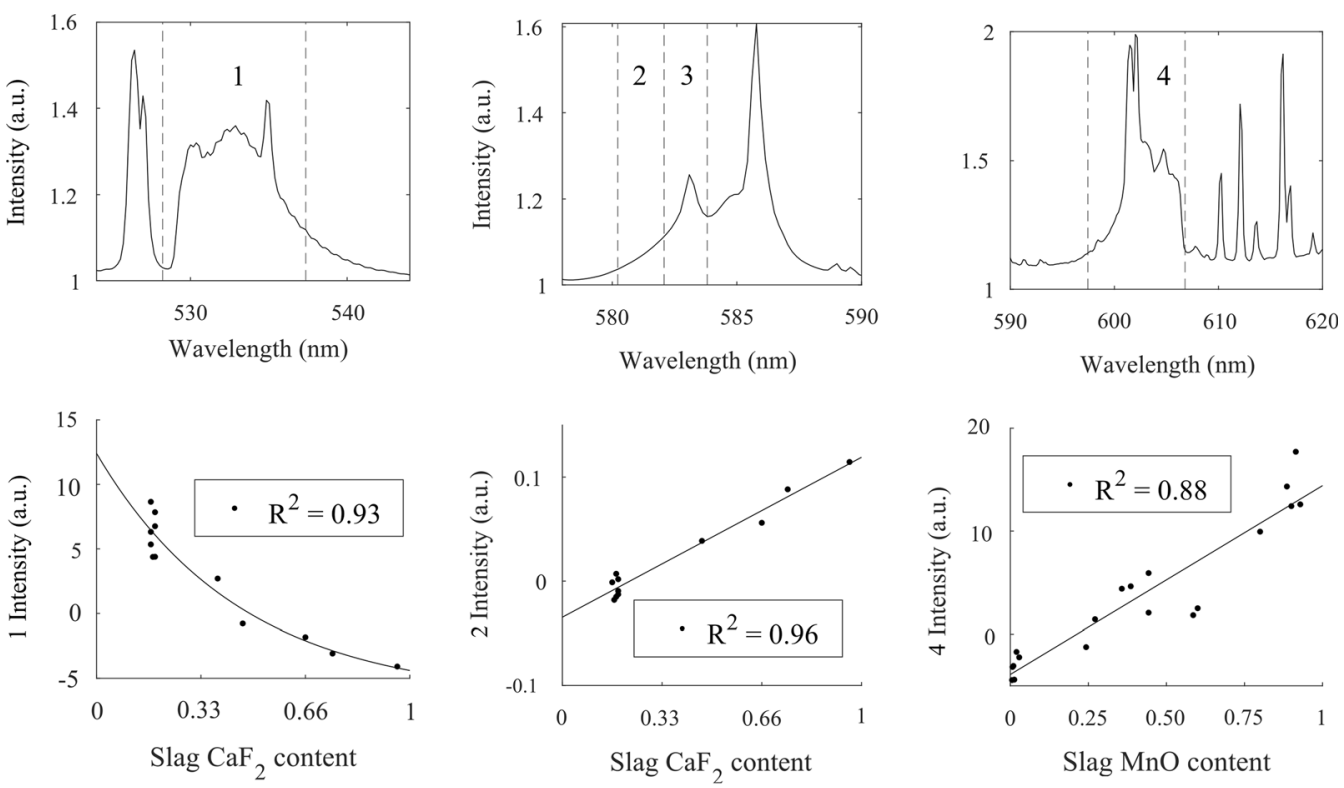

(a)

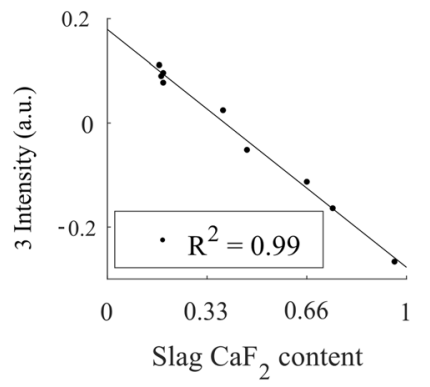

(b)

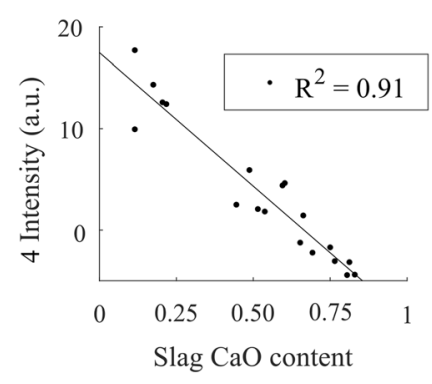

(c)

Fig. 7- (a) Marked wavelength range 1 at 528.2 to $537.4 \mathrm{~nm}$ with the relation between $\mathrm{CaF}_{2}$ content and intensity of the wavelength range 1 , $(b)$ marked wavelength ranges 2 and 3 at 580.2 to $582.1 \mathrm{~nm}$ and 582.1 to $583.8 \mathrm{~nm}$, respectively, with relations between CaF $\mathrm{F}_{2}$ content and intensity of the ranges 2 and 3, and $(c)$ marked wavelength range at 599.3 to $603.2 \mathrm{~nm}$ with the relation between range 4 and both $\mathrm{MnO}$ and $\mathrm{CaO}$ contents. The Ca I line at $534.947 \mathrm{~nm}$ has been excluded from the intensity of range 1 . The slag contents have been normalized with respect to the highest value for each slag component.

II, Mg I, Mn I, Cr I, Fe I, Al I, Si I, and V I lines could be identified for the slag composition analysis also from the broad spectra. In comparison to narrow spectra, all of the emission lines that were used in the broad spectrum analysis were within the wavelength range of a single spectrum. Hence, the line intensities could be used instead of FWHM values in the line ratio analysis for most cases. However, the FWHMs of Fe I, Mg I, Al I, and $\mathrm{Cr}$ I lines proved to be better to assess the $\mathrm{Fe}_{2} \mathrm{O}_{3} /$ $\mathrm{MgO}$ and $\mathrm{Al}_{2} \mathrm{O}_{3} / \mathrm{Cr}_{2} \mathrm{O}_{3}$ slag component ratios. The wavelength range $377-745 \mathrm{~nm}$ also holds one $\mathrm{Si}$ I emission line, with which the binary basicity $\mathrm{CaO} / \mathrm{SiO}_{2}$ of the slag could be assessed for the LF steel grades.

\section{Role of Spectral Resolution in the Analysis}

Both the chosen wavelength range of the spectrometer and the spectral resolution have a significant impact on the slag composition analysis. In this study, all of the spectra had 2048 pixels in a chosen wavelength range. Thus, the narrow spectra of Figure 2 have a spectral resolution of $0.022 \mathrm{~nm}$, whereas this value is $0.179 \mathrm{~nm}$ for the broad spectra of Figure 5. The finer the spectral resolution is, the more details of e.g., individual lines can be observed. Furthermore, neighboring emission lines can be more easily distinguished from one another with finer spectral resolution.

Figure 9(a) displays both broad and narrow spectra within 378 to $413 \mathrm{~nm}$. This wavelength range holds the most prominent emission lines for Si I and Al I above $390 \mathrm{~nm}$, which makes this wavelength range very important for the slag composition analysis. The wavelength range has also three intensive $\mathrm{Mg} \mathrm{I}$ lines around $383 \mathrm{~nm}$ and the two Ca II lines near $395 \mathrm{~nm}$ that were used in the analysis of Figure 3. The Ca II lines are clearly identifiable, but the Al I lines start to merge with the Ca II lines in the broad spectrum. The spectra of Figures 9(b) and (c) have a variety of Fe I, Cr I, Mn I, $\mathrm{Ca}$ I, and V I emission lines. In these spectra, the merging of emission lines is notable in the broad spectrum. However, the Mn I lines in this region proved to be essential for $\mathrm{MnO} / \mathrm{MgO}$ slag composition ratio analysis in the spectra where the lines were merged. In addition, also Fe I, Cr I, and Ca I could be separated from one another. 


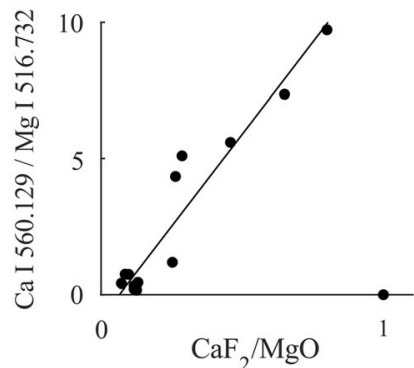

(a)

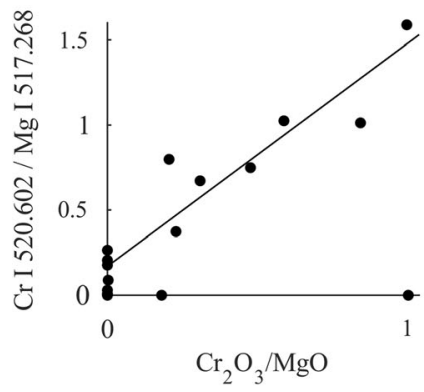

(d)

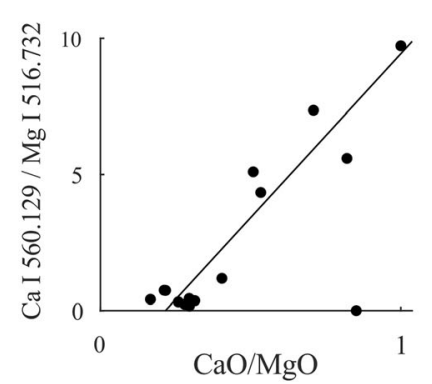

(b)

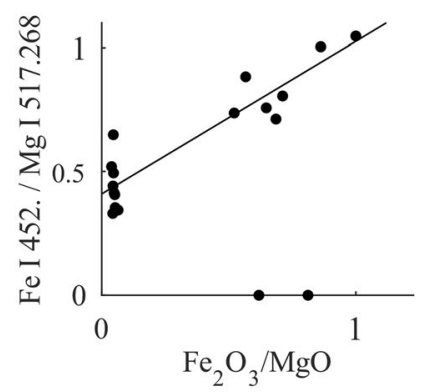

(e)

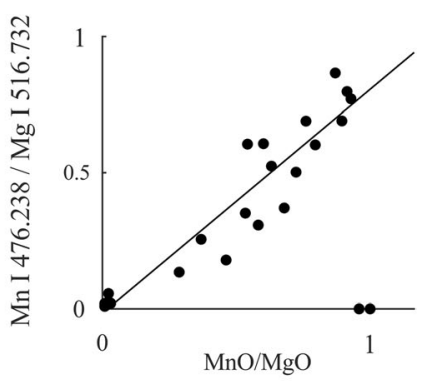

(c)

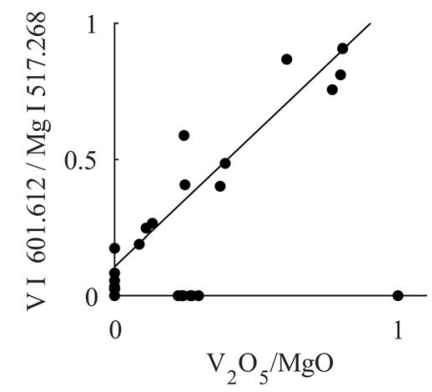

(f)

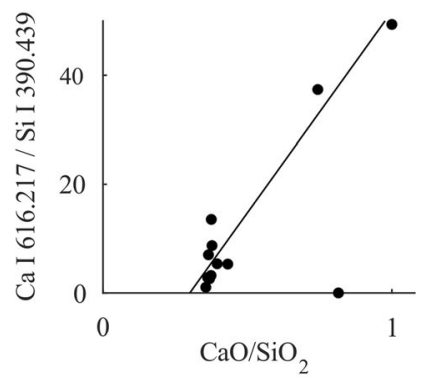

(g)

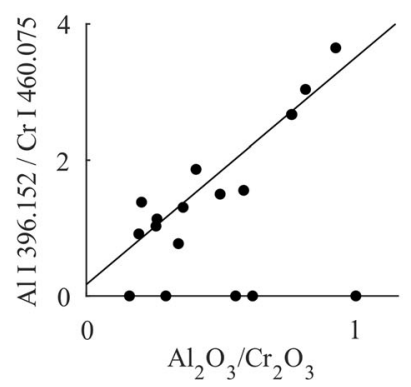

(h)

Fig. 8 - (a) to $(h)$ Example XRF slag composition ratios with respect to emission line ratios for several slag components. The emission line ratios have been obtained with line intensities, except for $\mathrm{Fe}_{2} \mathrm{O}_{3} / \mathrm{MgO}$ for which the emission lines were analyzed with FWHM values. The slag component ratios have been normalized with respect to the highest value for each ratio.

The three Mg I emission lines that were used in most of the emission line ratios reside in the wavelength range of Figure 9(d). These lines are centered at 516.732, 517.268, and $518.360 \mathrm{~nm}$ and do not overlap with any significantly intensive lines. Additionally, this wavelength range has three prominent $\mathrm{Cr}$ I lines at 520.450, 520.602, and $520.841 \mathrm{~nm}$. With the spectral resolution of $0.179 \mathrm{~nm}$, the $\mathrm{Cr} I$ lines form a single overlapping profile in the spectrum instead of three individual lines. The resolution of 0.022 $\mathrm{nm}$ allows these lines to form individual lines, which do not overlap with each other as much. These $\mathrm{Cr}$ I lines could not be reliably used with $0.179 \mathrm{~nm}$ resolution, and thus other Cr I lines were used instead. Similarly, the merging of $\mathrm{Ca}$ I emission lines can be seen in Figure 9(e) for $0.179 \mathrm{~nm}$ resolution. Figures $9(\mathrm{f})$ and (g) hold mainly $\mathrm{Ca}$ I emission lines regarding the slag composition analysis, whereas (h) shows several Cr I emission lines near the upper end of the wavelength range of this study.

A fine spectral resolution has many advantages, since emission lines can be identified and fitted more easily when the spectral resolution is as fine as possible. With the resolution of $0.022 \mathrm{~nm}$, significantly more emission lines could be used in the analysis than with $0.179 \mathrm{~nm}$. Fine resolution may also allow fitting single Gaussians instead of multiple Gaussians to resolve single emission lines, which makes the analysis more reliable and speeds up the computation. However, the number of spectrometers could be limited especially in industrial applications, and thus only a few spectrometers should be able to cover all relevant slag composition emission lines. This means that a single spectrometer will probably have to cover several hundred nanometers in order to capture relevant emission lines. For industrial applications, the optimal spectral resolution is probably between 0.022 and $0.179 \mathrm{~nm}$.

\section{CONCLUSION}

Optical emission spectra covering various wavelength ranges from UV to visible light were measured from a laboratory electric arc. Slag samples from industrial EAF and LF were exposed to the arc, revealing hundreds of optical emissions from both the atomic and molecular 


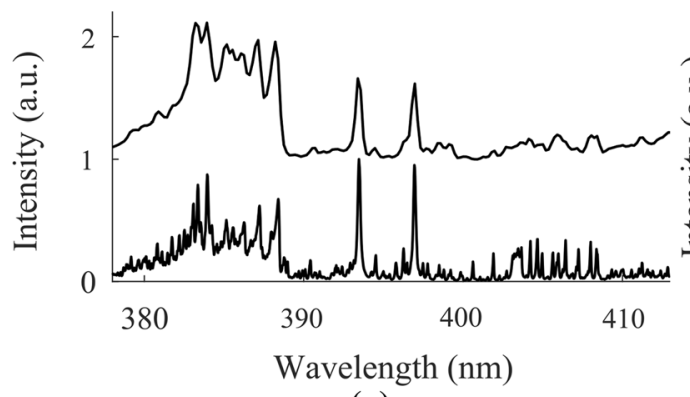

(a)

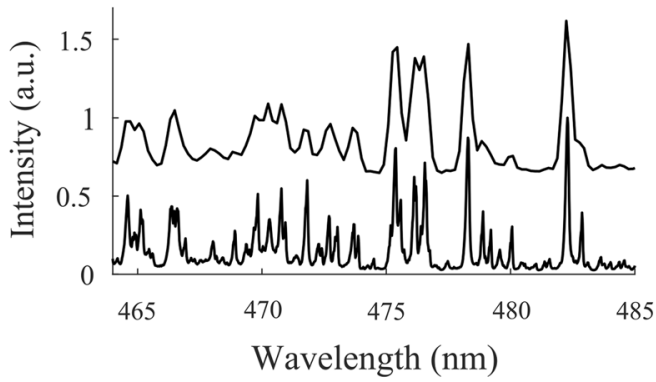

(c)

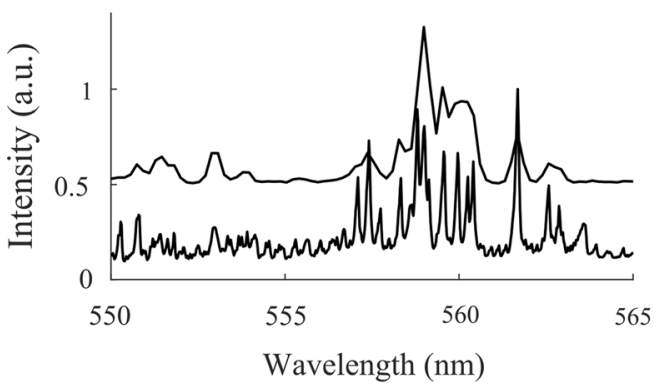

(e)

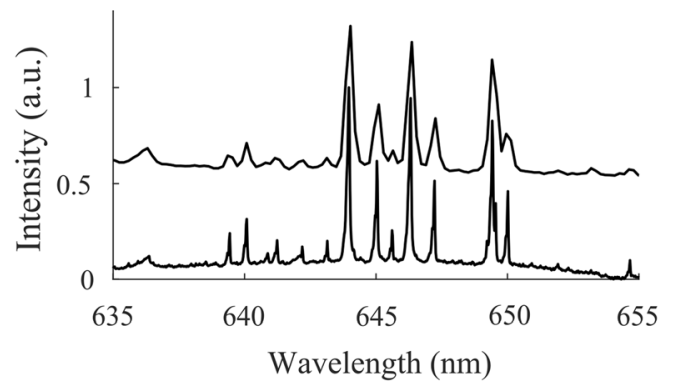

(g)

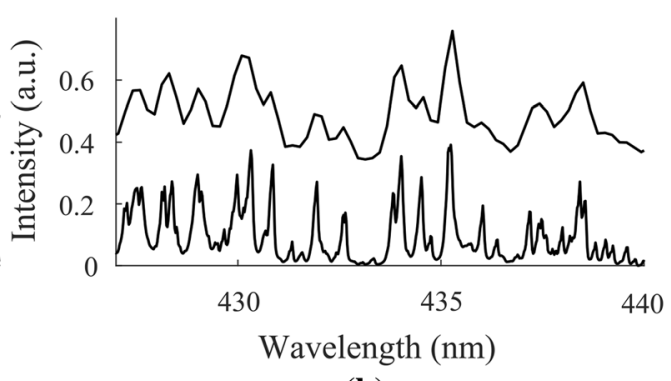

(b)

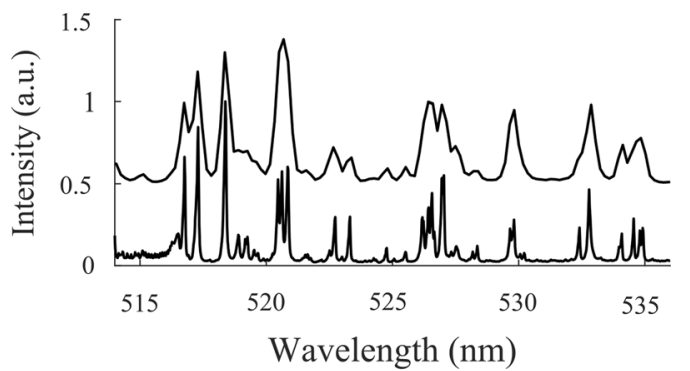

(d)

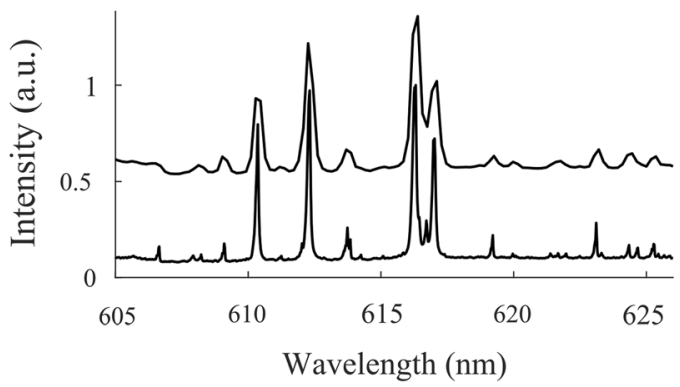

(f)

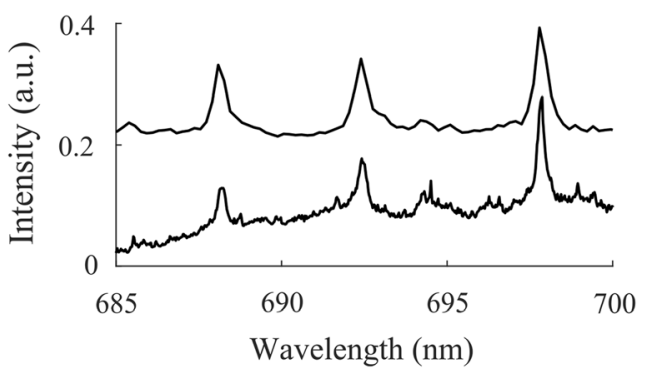

(h)

Fig. 9-Spectra within (a) 378 to $413 \mathrm{~nm},($ b) 427 to $440 \mathrm{~nm},(c) 464$ to $485 \mathrm{~nm},(d) 514$ to $536 \mathrm{~nm},($ e) 550 to $565 \mathrm{~nm},(f) 605$ to $626 \mathrm{~nm},(g) 635$ to $655 \mathrm{~nm}$, and $(h) 685$ to $700 \mathrm{~nm}$ with spectral resolutions of 0.179 (above) $\mathrm{nm}$ and $0.022 \mathrm{~nm}$ (below).

slag components. These optical emissions could be related to the composition of the slag samples either with ratio analysis or direct relation to specific slag components. Due to continuous optical emissions from industrial electric arcs of EAFs and LFs, OES shows promise as an online slag composition analysis method.

Dissociated $\mathrm{CaF}_{2}, \mathrm{CaO}, \mathrm{MgO}, \mathrm{MnO}, \mathrm{Fe}_{2} \mathrm{O}_{3}$, and $\mathrm{Cr}_{2} \mathrm{O}_{3}$ were identified to be the main source of atomic optical emissions in the spectra. Few prominent atomic emissions to analyze $\mathrm{SiO}_{2}$ and $\mathrm{Al}_{2} \mathrm{O}_{3}$ reside near the intersection of ultraviolet and visible light. Also, $\mathrm{V}_{2} \mathrm{O}_{5}$ and $\mathrm{Ni}$ amount of slag could be analyzed occasionally. Molecular optical emissions of $\mathrm{CaF}$ could be related to the $\mathrm{CaF}_{2}$ content of the slag. $\mathrm{CaF}_{2}$ is a common additive material in LFs, but because $\mathrm{CaF}$ emissions can be observed also from recombination of atomic calcium and fluorine, $\mathrm{CaF}$ optical emissions could be promising to quantify also the fluorine content of EAFs. The usability of emission lines was highly affected by spectral resolution. The closely packed emission lines could be separated with $0.022 \mathrm{~nm}$ resolution, whereas they merged together with $0.179 \mathrm{~nm}$ resolution. In an industrial application, spectrometers with fine enough spectral resolution and high enough spectral coverage from ultraviolet to near-infrared should be chosen. 


\section{ACKNOWLEDGMENTS}

We acknowledge the support of Research Fund for Coal and Steel under grant agreement No. 709923, Academy of Finland for Genome of Steel grant No. 311934, Business Finland for Grant No. 4478/31/2019.

\section{CONFLICT OF INTEREST}

The authors declare that they have no conflict of interest.

\section{FUNDING}

Open Access funding provided by University of Oulu including Oulu University Hospital.

\section{OPEN ACCESS}

This article is licensed under a Creative Commons Attribution 4.0 International License, which permits use, sharing, adaptation, distribution and reproduction in any medium or format, as long as you give appropriate credit to the original author(s) and the source, provide a link to the Creative Commons licence, and indicate if changes were made. The images or other third party material in this article are included in the article's Creative Commons licence, unless indicated otherwise in a credit line to the material. If material is not included in the article's Creative Commons licence and your intended use is not permitted by statutory regulation or exceeds the permitted use, you will need to obtain permission directly from the copyright holder. To view a copy of this licence, visit http://creat ivecommons.org/licenses/by/4.0/.

\section{APPENDIX}

Table AI for narrow spectrum and Table AII for broad spectrum emission line ratios that correlate XRF slag component ratios. $\mathrm{R}^{2}$ values have been obtained from linear fitting between XRF slag component ratios and OES emission line ratios. The wavelengths of the emission lines are indicated with nanometers in the ratios. $\mathrm{HS}$ is the number of slag samples that were used in the correlation analysis and $\mathrm{\# O}$ is the number of outliers that could not be used due to significant overlap with other emission lines or high self-absorption.

Table AI. Narrow Spectrum Table

\begin{tabular}{|c|c|c|c|c|c|c|c|c|c|c|c|}
\hline \multicolumn{4}{|c|}{$\mathrm{CaF}_{2} / \mathrm{MgO}($ grades $2 \& 3)$} & \multicolumn{4}{|c|}{$\mathrm{SiO}_{2} / \mathrm{MgO}($ grades $2 \& 3)$} & \multicolumn{4}{|c|}{$\mathrm{Cr}_{2} \mathrm{O}_{3} / \mathrm{MgO}($ grade 1$)$} \\
\hline $\mathrm{Ca} \mathrm{I} / \mathrm{Mg} \mathrm{I}$ & $\# \mathrm{~S}$ & $\# \mathrm{O}$ & $\mathrm{R}^{2}$ & Si I/Mg I & $\# \mathrm{~S}$ & $\# \mathrm{O}$ & $\mathrm{R}^{2}$ & $\mathrm{Cr} \mathrm{I} / \mathrm{Mg} \mathrm{I}$ & $\# \mathrm{~S}$ & $\# \mathrm{O}$ & $\mathrm{R}^{2}$ \\
\hline $452.69 / 277.83$ & 14 & 5 & 0.92 & $251.92 / 277.67$ & 13 & 6 & 0.82 & $434.45 / 518.36$ & 7 & 2 & 0.92 \\
\hline $452.69 / 277.98$ & 15 & 4 & 0.87 & $390.55 / 277.83$ & 13 & 6 & 0.88 & $461.61 / 278.14$ & 6 & 3 & 0.95 \\
\hline $452.69 / 383.83$ & 17 & 2 & 0.85 & $390.55 / 517.27$ & 16 & 3 & 0.85 & $476.43 / 278.14$ & 7 & 2 & 0.83 \\
\hline $452.69 / 516.73$ & 13 & 6 & 0.94 & $390.55 / 518.36$ & 14 & 5 & 0.90 & $520.45 / 277.98$ & 7 & 2 & 0.85 \\
\hline $518.89 / 516.73$ & 13 & 6 & 0.91 & \multicolumn{4}{|c|}{$\mathrm{Al}_{2} \mathrm{O}_{3} / \mathrm{MgO}(\operatorname{grades} 2 \& 3)$} & $520.45 / 278.30$ & 7 & 2 & 0.87 \\
\hline $559.01 / 382.94$ & 16 & 3 & 0.81 & $\mathrm{Al} \mathrm{I} / \mathrm{Mg} \mathrm{I}$ & $\# \mathrm{~S}$ & $\# \mathrm{O}$ & $\mathrm{R}^{2}$ & $520.45 / 382.94$ & 6 & 3 & 0.96 \\
\hline $612.22 / 277.67$ & 13 & 6 & 0.92 & $394.40 / 277.83$ & 15 & 4 & 0.83 & $520.45 / 516.73$ & 7 & 2 & 0.83 \\
\hline $612.22 / 277.83$ & 15 & 4 & 0.87 & $394.40 / 278.30$ & 16 & 3 & 0.86 & $520.45 / 517.27$ & 7 & 2 & 0.85 \\
\hline $612.22 / 278.30$ & 15 & 4 & 0.90 & $394.40 / 383.23$ & 16 & 3 & 0.92 & $520.45 / 518.36$ & 7 & 2 & 0.86 \\
\hline $612.22 / 516.73$ & 14 & 5 & 0.94 & $394.40 / 383.83$ & 16 & 3 & 0.89 & $520.84 / 517.27$ & 7 & 2 & 0.87 \\
\hline $616.22 / 277.67$ & 13 & 6 & 0.91 & $394.40 / 516.73$ & 14 & 5 & 0.85 & $534.58 / 278.30$ & 8 & 1 & 0.82 \\
\hline $616.22 / 277.83$ & 15 & 4 & 0.90 & $394.40 / 518.36$ & 13 & 6 & 0.88 & $534.58 / 382.94$ & 7 & 2 & 0.84 \\
\hline $616.22 / 278.30$ & 15 & 4 & 0.93 & $396.15 / 277.83$ & 14 & 5 & 0.91 & $534.58 / 517.27$ & 7 & 2 & 0.84 \\
\hline $616.22 / 516.73$ & 14 & 5 & 0.96 & $396.15 / 516.73$ & 14 & 5 & 0.89 & $697.98 / 278.30$ & 6 & 3 & 0.86 \\
\hline $643.91 / 517.27$ & 14 & 5 & 0.81 & $396.15 / 517.27$ & 14 & 5 & 0.86 & \multicolumn{4}{|c|}{$\mathrm{V}_{2} \mathrm{O}_{5} / \mathrm{MgO}($ grade $1 \& 3)$} \\
\hline $646.26 / 277.67$ & 14 & 5 & 0.89 & $396.15 / 518.36$ & 15 & 4 & 0.73 & $\mathrm{~V} \mathrm{I} / \mathrm{Mg} \mathrm{I}$ & $\# \mathrm{~S}$ & $\# \mathrm{O}$ & $\mathrm{R}^{2}$ \\
\hline $646.26 / 517.27$ & 15 & 4 & 0.97 & \multicolumn{4}{|c|}{$\mathrm{MnO} / \mathrm{MgO}($ grades $2 \& 3)$} & $475.39 / 382.94$ & 11 & 8 & 0.85 \\
\hline $646.26 / 518.36$ & 15 & 4 & 0.90 & $\mathrm{Mn} \mathrm{I/Mg} \mathrm{I}$ & $\# \mathrm{~S}$ & $\# \mathrm{O}$ & $\mathrm{R}^{2}$ & $600.26 / 518.36$ & 13 & 6 & 0.85 \\
\hline $\mathrm{Ca} \mathrm{II} / \mathrm{Mg} \mathrm{I}$ & $\# \mathrm{~S}$ & $\# \mathrm{O}$ & $\mathrm{R}^{2}$ & $403.45 / 383.83$ & 13 & 6 & 0.88 & \multicolumn{4}{|c|}{$\mathrm{Ni} / \mathrm{MgO}($ grade $1 \& 3)$} \\
\hline $393.37 / 278.23$ & 16 & 3 & 0.90 & $403.45 / 518.36$ & 15 & 4 & 0.84 & $\mathrm{Ni} \mathrm{I/Mg} \mathrm{I}$ & $\# \mathrm{~S}$ & $\# \mathrm{O}$ & $\mathrm{R}^{2}$ \\
\hline $393.37 / 382.96$ & 18 & 1 & 0.83 & $404.88 / 278.30$ & 15 & 4 & 0.83 & $341.48 / 277.67$ & 13 & 6 & 0.84 \\
\hline $393.37 / 383.23$ & 15 & 4 & 0.87 & $404.88 / 516.73$ & 15 & 4 & 0.83 & \multicolumn{4}{|c|}{$\mathrm{CaO} / \mathrm{MgO}($ grades $2 \& 3)$} \\
\hline $393.37 / 383.83$ & 17 & 2 & 0.82 & $404.88 / 517.27$ & 15 & 4 & 0.82 & $\mathrm{Ca} \mathrm{I} / \mathrm{Mg} \mathrm{I}$ & $\# \mathrm{~S}$ & $\# \mathrm{O}$ & $\mathrm{R}^{2}$ \\
\hline $393.37 / 516.73$ & 15 & 4 & 0.97 & \multicolumn{4}{|c|}{$\mathrm{Fe}_{2} \mathrm{O}_{3} / \mathrm{MgO}($ grades $1 \& 2)$} & $452.69 / 277.83$ & 14 & 5 & 0.92 \\
\hline $393.37 / 517.27$ & 15 & 4 & 0.97 & $\mathrm{Fe} \mathrm{I} / \mathrm{Mg} \mathrm{I}$ & $\# \mathrm{~S}$ & $\# \mathrm{O}$ & $\mathrm{R}^{2}$ & $452.69 / 277.98$ & 14 & 5 & 0.95 \\
\hline $393.37 / 518.36$ & 15 & 4 & 0.94 & $438.35 / 517.27$ & 10 & 8 & 0.96 & $452.69 / 383.83$ & 16 & 3 & 0.93 \\
\hline $396.85 / 278.30$ & 16 & 3 & 0.94 & $438.35 / 518.36$ & 10 & 8 & 0.96 & $452.69 / 516.73$ & 15 & 4 & 0.92 \\
\hline $396.85 / 382.94$ & 17 & 2 & 0.81 & $532.42 / 277.83$ & 13 & 5 & 0.82 & $518.89 / 516.73$ & 13 & 6 & 0.88 \\
\hline $396.85 / 383.23$ & 15 & 4 & 0.91 & $533.99 / 277.67$ & 12 & 6 & 0.86 & $559.01 / 382.94$ & 17 & 2 & 0.36 \\
\hline $396.85 / 383.83$ & 17 & 2 & 0.87 & \multicolumn{4}{|c|}{$\mathrm{Fe}_{2} \mathrm{O}_{3} / \mathrm{MgO}($ grade 3$)$} & $612.22 / 277.83$ & 16 & 3 & 0.82 \\
\hline
\end{tabular}


Table AI. continued

\begin{tabular}{|c|c|c|c|c|c|c|c|c|c|c|c|}
\hline \multicolumn{4}{|c|}{$\mathrm{CaF}_{2} / \mathrm{MgO}($ grades 2\&3) } & \multicolumn{4}{|c|}{$\mathrm{SiO}_{2} / \mathrm{MgO}$ (grades $2 \& 3$ ) } & \multicolumn{4}{|c|}{$\mathrm{Cr}_{2} \mathrm{O}_{3} / \mathrm{MgO}($ grade 1$)$} \\
\hline $\mathrm{Ca} \mathrm{I/Mg} \mathrm{I}$ & $\# \mathrm{~S}$ & $\# \mathrm{O}$ & $\mathrm{R}^{2}$ & Si I/Mg I & $\# \mathrm{~S}$ & $\# \mathrm{O}$ & $\mathrm{R}^{2}$ & $\mathrm{Cr} \mathrm{I/Mg} \mathrm{I}$ & $\# \mathrm{~S}$ & $\# \mathrm{O}$ & $\mathrm{R}^{2}$ \\
\hline $396.85 / 516.73$ & 15 & 4 & 0.98 & $\mathrm{Fe} \mathrm{I} / \mathrm{Mg} \mathrm{I}$ & $\# \mathrm{~S}$ & $\# \mathrm{O}$ & $\mathrm{R}^{2}$ & $612.22 / 278.30$ & 16 & 3 & 0.90 \\
\hline $396.85 / 517.27$ & 15 & 4 & 0.96 & $414.39 / 278.30$ & 8 & 2 & 0.92 & $612.22 / 516.73$ & 13 & 6 & 0.92 \\
\hline $396.85 / 518.36$ & 15 & 4 & 0.90 & $440.48 / 383.83$ & 6 & 4 & 0.97 & $616.22 / 277.67$ & 14 & 5 & 0.79 \\
\hline \multicolumn{4}{|c|}{$\mathrm{Cr}_{2} \mathrm{O}_{3} / \mathrm{MgO}($ grade 3$)$} & $534.10 / 277.67$ & 7 & 3 & 0.80 & $616.22 / 277.83$ & 16 & 3 & 0.82 \\
\hline $\mathrm{Cr} \mathrm{I} / \mathrm{Mg} \mathrm{I}$ & $\# \mathrm{~S}$ & $\# \mathrm{O}$ & $\mathrm{R}^{2}$ & $534.10 / 278.30$ & 8 & 2 & 0.90 & $616.22 / 278.30$ & 16 & 3 & 0.91 \\
\hline $434.45 / 518.36$ & 7 & 3 & 0.98 & $534.10 / 516.73$ & 6 & 4 & 0.88 & $616.22 / 516.73$ & 13 & 6 & 0.93 \\
\hline $435.10 / 278.14$ & 7 & 3 & 0.84 & $534.10 / 518.36$ & 8 & 2 & 0.82 & $643.91 / 517.27$ & 14 & 5 & 0.83 \\
\hline $435.10 / 518.36$ & 7 & 3 & 0.89 & & & & & $646.26 / 277.67$ & 14 & 5 & 0.91 \\
\hline $435.18 / 518.36$ & 7 & 3 & 0.93 & & & & & $646.26 / 517.27$ & 15 & 4 & 0.93 \\
\hline $520.45 / 516.73$ & 8 & 2 & 0.81 & & & & & $646.26 / 518.36$ & 16 & 3 & 0.86 \\
\hline $520.45 / 518.36$ & 8 & 2 & 0.83 & & & & & $\mathrm{Ca} \mathrm{II/Mg} \mathrm{I}$ & $\# \mathrm{~S}$ & $\# \mathrm{O}$ & $\mathrm{R}^{2}$ \\
\hline $520.84 / 517.27$ & 8 & 2 & 0.88 & & & & & $393.37 / 278.30$ & 16 & 3 & 0.85 \\
\hline $520.84 / 518.36$ & 7 & 3 & 0.86 & & & & & $393.37 / 382.94$ & 13 & 6 & 0.85 \\
\hline $529.80 / 382.94$ & 7 & 3 & 0.92 & & & & & $393.37 / 383.23$ & 15 & 4 & 0.89 \\
\hline $529.80 / 383.23$ & 7 & 3 & 0.99 & & & & & $393.37 / 383.83$ & 19 & 0 & 0.85 \\
\hline \multirow[t]{8}{*}{$534.58 / 278.14$} & 6 & 4 & 0.94 & & & & & $93.37 / 516.73$ & 15 & 4 & 0.92 \\
\hline & & & & & & & & $393.37 / 517.27$ & 15 & 4 & 0.93 \\
\hline & & & & & & & & $393.37 / 518.36$ & 15 & 4 & 0.91 \\
\hline & & & & & & & & $396.85 / 278.30$ & 16 & 3 & 0.86 \\
\hline & & & & & & & & $396.85 / 382.94$ & 13 & 6 & 0.87 \\
\hline & & & & & & & & $396.85 / 383.23$ & 15 & 4 & 0.86 \\
\hline & & & & & & & & $396.85 / 383.83$ & 19 & 0 & 0.85 \\
\hline & & & & & & & & $396.85 / 516.73$ & 15 & 4 & 0.94 \\
\hline
\end{tabular}

Table AII. Broad Spectrum Table

\begin{tabular}{|c|c|c|c|c|c|c|c|}
\hline \multicolumn{4}{|c|}{$\mathrm{CaF}_{2} / \mathrm{MgO}($ Grades $2 \& 3)$} & \multicolumn{4}{|c|}{$\mathrm{Cr}_{2} \mathrm{O}_{3} / \mathrm{MgO}($ grades $2 \& 3$ ) } \\
\hline $\mathrm{Ca} \mathrm{I/Mg} \mathrm{I}$ & $\# \mathrm{~S}$ & $\# \mathrm{O}$ & $\mathrm{R}^{2}$ & $\mathrm{Cr} \mathrm{I/Mg} \mathrm{I}$ & $\# \mathrm{~S}$ & $\# \mathrm{O}$ & $\mathrm{R}^{2}$ \\
\hline $558.12 / 516.73$ & 14 & 2 & 0.85 & $520.60 / 517.27$ & 13 & 3 & 0.89 \\
\hline $560.13 / 516.73$ & 15 & 1 & 0.92 & $520.60 / 518.36$ & 13 & 3 & 0.84 \\
\hline $610.27 / 516.73$ & 14 & 2 & 0.85 & \multicolumn{4}{|c|}{$\mathrm{Fe}_{2} \mathrm{O}_{3} / \mathrm{MgO}($ grades $2 \& 3)$} \\
\hline $612.22 / 516.73$ & 14 & 2 & 0.87 & $\mathrm{Fe} \mathrm{I} / \mathrm{Mg} \mathrm{I}$ & $\# \mathrm{~S}$ & $\# \mathrm{O}$ & $\mathrm{R}^{2}$ \\
\hline $643.91 / 516.73$ & 14 & 2 & 0.88 & $452.86 / 516.73$ & 16 & 2 & 0.89 \\
\hline $644.98 / 516.73$ & 14 & 2 & 0.92 & $452.86 / 517.27$ & 16 & 2 & 0.85 \\
\hline $644.98 / 517.27$ & 14 & 2 & 0.83 & $452.86 / 518.36$ & 15 & 3 & 0.88 \\
\hline $645.56 / 516.73$ & 14 & 2 & 0.85 & $532.42 / 517.27$ & 16 & 2 & 0.84 \\
\hline $646.26 / 516.73$ & 14 & 2 & 0.89 & $532.42 / 518.36$ & 15 & 3 & 0.92 \\
\hline $647.17 / 516.73$ & 14 & 2 & 0.89 & $533.99 / 517.27$ & 15 & 3 & 0.86 \\
\hline $649.38 / 516.73$ & 14 & 2 & 0.89 & \multicolumn{4}{|c|}{$\mathrm{V}_{2} \mathrm{O}_{5} / \mathrm{MgO}($ grades $1 \& 2 \& 3)$} \\
\hline \multicolumn{4}{|c|}{$\mathrm{CaO} / \mathrm{MgO}($ Grades $2 \& 3)$} & $\mathrm{V} \mathrm{I} / \mathrm{Mg} \mathrm{I}$ & $\# \mathrm{~S}$ & $\# \mathrm{O}$ & $\mathrm{R}^{2}$ \\
\hline $\mathrm{Ca} \mathrm{I} / \mathrm{Mg} \mathrm{I}$ & $\# \mathrm{~S}$ & $\# \mathrm{O}$ & $\mathrm{R}^{2}$ & $601.61 / 516.73$ & 15 & 10 & 0.85 \\
\hline $487.81 / 518.36$ & 13 & 3 & 0.88 & $601.61 / 517.27$ & 17 & 8 & 0.91 \\
\hline $560.13 / 516.73$ & 15 & 1 & 0.90 & $601.61 / 518.36$ & 15 & 10 & 0.92 \\
\hline $610.27 / 516.73$ & 14 & 2 & 0.86 & $602.18 / 517.27$ & 18 & 7 & 0.82 \\
\hline $610.27 / 517.27$ & 13 & 3 & 0.84 & $602.18 / 518.36$ & 17 & 8 & 0.85 \\
\hline $645.56 / 517.27$ & 14 & 2 & 0.81 & \multicolumn{4}{|c|}{$\mathrm{Al}_{2} \mathrm{O}_{3} / \mathrm{Cr}_{2} \mathrm{O}_{3}($ grades $1 \& 3)$} \\
\hline $649.97 / 516.73$ & 14 & 2 & 0.88 & $\mathrm{Al} \mathrm{I} / \mathrm{Cr} \mathrm{I}$ & $\# \mathrm{~S}$ & $\# \mathrm{O}$ & $\mathrm{R}^{2}$ \\
\hline \multicolumn{4}{|c|}{$\mathrm{MnO} / \mathrm{MgO}($ Grades $1 \& 2 \& 3)$} & $396.15 / 453.57$ & 13 & 5 & 0.83 \\
\hline $\mathrm{Mn} \mathrm{I} / \mathrm{Mg} \mathrm{I}$ & $\# \mathrm{~S}$ & $\# \mathrm{O}$ & $\mathrm{R}^{2}$ & $396.15 / 454.60$ & 14 & 4 & 0.82 \\
\hline $475.40 / 517.27$ & 22 & 3 & 0.84 & $396.15 / 460.08$ & 13 & 5 & 0.87 \\
\hline $475.40 / 518.36$ & 22 & 3 & 0.83 & $396.15 / 578.79$ & 12 & 6 & 0.83 \\
\hline $476.24 / 516.73$ & 23 & 2 & 0.90 & $394.40 / 534.58$ & 12 & 6 & 0.87 \\
\hline $476.64 / 516.73$ & 22 & 3 & 0.84 & $394.40 / 578.79$ & 13 & 5 & 0.81 \\
\hline $478.34 / 516.73$ & 22 & 3 & 0.89 & \multicolumn{4}{|c|}{$\mathrm{CaO} / \mathrm{SiO}_{2}($ grades $2 \& 3)$} \\
\hline $478.34 / 518.36$ & 22 & 3 & 0.85 & $\mathrm{Ca} \mathrm{I} / \mathrm{Si} \mathrm{I}$ & $\# \mathrm{~S}$ & $\# \mathrm{O}$ & $\mathrm{R}^{2}$ \\
\hline $482.35 / 517.27$ & 22 & 3 & 0.81 & $616.22 / 390.44$ & 11 & 1 & 0.94 \\
\hline $482.35 / 518.36$ & 20 & 5 & 0.84 & $616.91 / 390.44$ & 11 & 1 & 0.90 \\
\hline
\end{tabular}


Table AII. continued

\begin{tabular}{|c|c|c|c|c|c|c|c|}
\hline \multicolumn{4}{|c|}{$\mathrm{CaF}_{2} / \mathrm{MgO}($ Grades $2 \& 3)$} & \multicolumn{4}{|c|}{$\mathrm{Cr}_{2} \mathrm{O}_{3} / \mathrm{MgO}($ grades $2 \& 3)$} \\
\hline \multirow[t]{5}{*}{$\mathrm{Ca} \mathrm{I/Mg} \mathrm{I}$} & $\# \mathrm{~S}$ & $\# \mathrm{O}$ & $\mathrm{R}^{2}$ & $\mathrm{Cr} \mathrm{I} / \mathrm{Mg} \mathrm{I}$ & $\# \mathrm{~S}$ & $\# \mathrm{O}$ & $\mathrm{R}^{2}$ \\
\hline & & & & $647.17 / 390.44$ & 11 & 1 & 0.84 \\
\hline & & & & $671.77 / 390.44$ & 11 & 1 & 0.87 \\
\hline & & & & $\mathrm{Ca} \mathrm{II/Si} \mathrm{I}$ & $\# \mathrm{~S}$ & $\# \mathrm{O}$ & $\mathrm{R}^{2}$ \\
\hline & & & & $396.85 / 390.44$ & 10 & 2 & 0.93 \\
\hline
\end{tabular}

\section{REFERENCES}

1. L. Holappa: Metals, 2020, vol. 10 (9), p. 1117.

2. V. Vogl, M. Åhman, and L.J. Nilsson: J. Cleaner Prod., 2018, vol. 203, pp. 736-45.

3. M. Pei, M. Petäjäniemi, A. Regnell, and O. Wijk: Metals, 2020, vol. 10 (7), p. 972

4. H-.J. Odenthal, A. Kemminger, F. Krause, L. Sankowski, N. Uebber, and N. Vogl: Steel Res. Int., 2018, vol. 89 (1), p. 1700098.

5. J. An, Y. Huang, M. Wu, and J. She: IEEE Trans. Ind. Inform., 2020, vol. 16 (12), pp. 7658-70.

6. M. Aula, A. Leppänen, J. Roininen, E-.P. Heikkinen, K. Vallo, T. Fabritius, and M. Huttula: Metall. Mater. Trans. B, 2014, vol. 45 (3), pp. 839-49.

7. M. Aula, A. Mäkinen, A. Leppänen, M. Huttula, and T. Fabritius: ISIJ Int., 2015, vol. 55 (8), pp. 1702-10.

8. H. Pauna, M. Aula, J. Seehausen, J-.S. Klung, M. Huttula, and T. Fabritius: Steel Res. Int., 2020, vol. 91, p. 2000051.

9. H. Pauna, M. Aula, J. Seehausen, J-.S. Klung, M. Huttula, and T. Fabritius: ISIJ Int., 2020, vol. 60 (9), pp. 1985-92.

10. Y. Han, C. Zhang, L. Wang, and Y. Zhang: IEEE Trans. Ind. Inform., 2020, vol. 16 (4), pp. 2640-50.

11. A. Picon, A. Vicente, S. Rodriguez-Vaamonde, J. Armentia, J.A. Arteche, and I. Macaya: IEEE Trans. Ind. Inform., 2018, vol. 14 (8), pp. 3506-12.

12. A. Kramida, Yu. Ralchenko, J. Reader and NIST ASD Team: NIST Atomic Spectra Database. https://www.nist.gov/pml/ato mic-spectra-database. Accessed 26 March 2021

13. C. Aragón and J.A. Aguilera: Spectrochim. Acta Part B, 2018, vol. 63 (9), pp. 893-916.

14. R.D. Cowan and G.H. Dieke: Rev. Mod. Phys., 1948, vol. 20 (2), pp. $418-55$.
15. H. Pauna, T. Willms, M. Aula, T. Echterhof, M. Huttula, and T. Fabritius: Plasma Res. Express, 2019, vol. 1 (3), p. 035007.

16. A.A. Bol'shakov, X. Mao, R.E. Russo, J. Anal. At. Spectrom. 32(3), 657-70 (2017).

17. M. Gaft, L. Nagli, N. Eliezer, Y. Groisman, and O. Forni: Spectrochim. Acta Part B, 2014, vol. 98, pp. 39-47.

18. C. Alvarez-Llamas, J. Pisonero, and N. Bordel: Spectrochim. Acta Part B, 2016, vol. 123, pp. 157-62.

19. C. Alvarez-Llamas, J. Pisonero, and N. Bordel: J. Anal. At. Spectrom., 2017, vol. 32 (1), pp. 162-66.

20. P. Pořizka, S. Kaski, A. Hrdlička, P. Modlitbová, L. Sládková, H. Häkkänen, D. Prochazka, J. Novotný, P. Gadas, L. Čelko, K. Novotný, and J. Kaiser: J. Anal. At. Spectrom., 2017, vol. 32 (10), pp. 1966-74.

21. D.S. Vogt, S. Schröder, K. Rammelkamp, P.B. Hansen, S. Kubitza, and H-.W. Hübers: Icarus, 2020, vol. 335, p. 113393.

22. J. Papish, L.E. Hoag, and W.E. Snee: Ind. Eng. Chem., Anal. Ed., 1930, vol. 2 (3), pp. 263-64.

23. O.B. Troshkina: J. Appl. Spectrosc., 1971, vol. 14 (4), pp. 430-37.

24. A. Mitscherlich: Ann. Phys. Chem., 1864, vol. 121, pp. 459-88.

25. K.R. Bindu and E.I. Anila: J. Fluoresc., 2015, vol. 25 (4), pp. $795-$ 801.

26. V.M. Igba, I. Ahemen, A.N. Amah, F.B. Dejene, R. Sha'Ato, A. Reyes-Rojas, J.A. Duarte-Moller, J.R. Parra-Michel, Opt. Mater. Express 10(11), 2877-95 (2020).

27. B. Pejjai, V.R. Minnam Reddy, K. Seku, T.R.R. Kotte, and C. Park: Optik, 2017, vol. 130, pp. 608-18.

28. X. Zhang, Z. Zhu, Z. Guo, Z. Sun, and Y. Chen: Chem. Eng. J., 2019, vol. 356 , pp. $413-22$.

Publisher's Note Springer Nature remains neutral with regard to jurisdictional claims in published maps and institutional affiliations. 